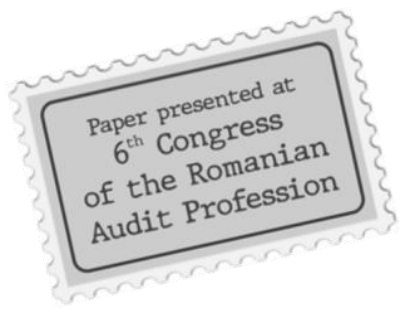

Using the GiPlot Online Interactive

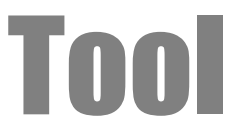

\section{to Explore Business and Financial Data in the Context of the Ex Post Component of the Audit}

Univ. prof. Dinu AIRINEI, Ph. D., "Alexandru loan Cuza" University of laşi (UAIC), Faculty of Economics and Business Administration (FEAA),

Department of Accounting, Business Information Systems and Statistics (CIES), e-mail: adinu@uaic.ro

Lecturer Daniel HOMOCIANU, Ph. D. "Alexandru loan Cuza" University of laşi (UAIC), Faculty of Economics and Business Administration (FEAA),

Department of Accounting, Business Information

Systems and Statistics (CIES), e-mail: dan.homocianu@gmail.com

\section{Albstract}

In the context of dealing with an increasing volume of business, financial and audit data, this paper presents some advantages of using an interactive cloud computing-based tool, namely GiPlot, developed using Google technology, available for free use and originally meant for representing and visually exploring general purpose data. The tool itself is a sort of visual interactive simulation (VIS) application which belongs to the broader category of prescriptive Business Intelligence. It relies on online environments and data sources (e.g. Google Drive, Google Sheets) and also on the idea of collaboration, transparency and support for replication of results. The usage scenarios presented in the paper include time series and correlation diagrams, in the context of the overall objective of the paper, namely to justify the possibilities of using the GiPlot tool for economic and financial data, especially when the ex post component of the audit is concerned.

Keywords: ex post audit, exploring business and financial data, GiPlot, usage scenarios, advantages

JEL Classification: C32, C88, Y10

To cite this article:

Airinei, D., Homocianu, D. (2019), Using the GiPlot Online Interactive Tool to Explore Business and Financial Data in the Context of the Ex Post Component of the Audit, Audit Financiar, vol. XVII, no. 4(156)/2019, pp. 628-641,

DOI: 10.20869/AUDITF/2019/156/023

To link this article:

http://dx.doi.org/10.20869/AUDITF/2019/156/023

Received: 12.07.2019

Revised: 29.07.2019

Accepted: 14.09.2019 


\section{Introduction}

This paper argues the importance of an interactive representation tool called "GiPlot" for the audit work, especially when used in conjunction with historical data in the context of the ex-post component of the audit, which mainly targets operations or decisions (legislatie.just.ro) , after their completion. The ex-post or the a posteriori audit (ier.gov.ro) is exercised after the financial transaction and usually involves three types: the performance audit focused on the $3 \mathrm{E}$ (economy, effectiveness and efficiency), the financial audit and the audit as examination by the Supreme Audit Institution, namely the Romanian Court of Accounts (curteadeconturi.ro), which also has judicial functions and issues assessments regarding the responsibility of the persons involved in the management of the public money.

The representation options of the GiPlot tool meet the need for comparison and visual exploration of any specialist in audit activities. The time-series and correlation analysis facilities are added to the comparative visualization, biaxial filtering and immediate feed-back possibilities in the form of data related to a point on the graph, all in real time and in an online environment.

\section{Background and literature review}

The current paper is based on the previous contributions of the authors (Homocianu \& Airinei, 2015; Homocianu \& Homocianu, 2019) concerning the development and implementation of online interactive instruments for simulation based on Cloud Computing and designed for analyzing and interpreting different types of data and consequently providing a consistent support for drawing scientific conclusions in various fields and decisionmaking in business and economics (Sharda et.al, 2014). These contributions are fully consistent with the early preoccupations of other researchers about spectral analysis in business and economics. (Harvey, 1975), which is especially important for the study of chronological series, which are known to exhibit a cyclic behavior - e.g. spectral analysis of stock prices (Bertoneche, 1979).

The core of GiPlot and all its functionalities have already been used in two studies. The first study (Homocianu et.al., 2018) focused on the forest fund's dynamics in Romania. In this study, the basic functions of GiPlot have been involved in combination with other visualization and data mining tools, starting from multiple and multi-source time series (The Romanian Court of Accounts, Ministry of Environment, National Bank of Romania, National Institute of Statistics, Global Forest Watch and Transparency International - Global Coalition Against Corruption). The data series selection option, the metaphor of the Cartesian System of Axis together with the two-edge horizontal slider bar corresponding to the $X$ axis provide interactive and intuitive representation possibilities for both the time series and the correlation charts.

The second study (Homocianu et. al., 2019) concerns a comparative analysis of scientific publications in journals with impact factor using Natural Language Processing (NLP) tools and derivation of conclusions regarding the most common concepts at the boundary between Decision Support Systems (DSS) and Business Intelligence (BI). Here, the GiPlot tool

(sites.google.com/site/supp4giplot/try-it) has been used for an additional analysis based on two time-series with the frequency in time (years) for publications, considering those two topics above and the same type of journals. This analysis has clearly highlighted a longer history of Business Intelligence, starting from publications dating back from 1975.

\section{Data and methods used}

In the present paper we used the data from the following sources: The Financial Supervisory Authority Romania (ASF) and The Stock Exchange from Bucharest Romania (BVB).

For both sources, after minimal processing applied to the initial data imported in the spreadsheet format, we have argued the possibilities of working with time series. For the second source, we also presented some examples of correlation diagrams.

In the case of the first data source ${ }^{1}$, we have proposed to obtain two online charts to interactively show an ex post analysis of the evolution of certain aggregations corresponding to the following indicators in relation to certain intervals selected for the graduation year: (1) the

\footnotetext{
${ }^{1}$ http://asfromania.ro/files/capital/auditori_financiari/ Auditorifinanciari-PF.xls
} 
yearly number of graduates (individuals) of the financial audit officer training stage, and (2) the annual number of distinct counties which these graduates are coming from.

We have previously applied an extraction function for substrings (RIGHT) and then we generated two pivot tables, starting from which we initiated all the representation steps using the GiPlot online tool.

In the case of the second data source ${ }^{1}$, first of all we have proposed to make an ex post analysis of the minimum and maximum points and support several arguments using interactive graphical representations that confirm the existence of a critical point in 2007, after Romania's accession to the European Union and before the start of the global economic and financial crisis. Additionally, we had the intention to obtain the graphical demonstration of at least one correlation between two of the variables involved in the ex post analysis mentioned above.

\section{Results and discussions}

The first scenario is built to argue the possibilities of ex post analysis in the work of a financial auditor, guiding us according to the principles of transparency and interactivity, and starting from gross evidence data (in this case, data about graduates of the financial audit officer training stage as persons) which are then aggregated to generate certain quantifications in relation to different reference moments available and extracted from the data concerned.

In this first scenario corresponding to the first dataset referred to in the previous section, we first applied the RIGHT extraction function (Figure no, 1) to determine the year (last 4 characters) of the graduation certificate starting from a composite field that stores both the number and the release date (Microsoft Office Excel).

\section{Figure no. 1. Extracting the year of obtaining the graduation certificate with the RIGHT function available in} both Microsoft Office Excel and Google Sheets online spreadsheets

\begin{tabular}{|c|c|c|c|}
\hline \multicolumn{2}{|c|}{$\mathrm{J} 2$} & $\boldsymbol{f}_{\boldsymbol{x}}$ & $=\mathrm{RIGHT}(12,4)$ \\
\hline \hline 4 & $\mathrm{H}$ & $\mathrm{I}$ & $\mathrm{J}$ \\
\hline & $\begin{array}{c}\text { Nr. si data } \\
\text { carnetului de } \\
\text { auditor }\end{array}$ & $\begin{array}{c}\mathrm{Nr} \text { si data } \\
\text { certificatului de } \\
\text { absolvire }\end{array}$ & An_abs \\
\hline 2 & $2719 / 27.01 .2009$ & $051 / 27.09 .2010$ & 2010 \\
\hline 3 & $347 / 01.03 .2001$ & $160 / 12.04 .2005$ & 2005 \\
\hline 4 & $2030 / 27.03 .2007$ & CERTIFICAT/16-18.03.2012 & 2012 \\
\hline
\end{tabular}

Source: Own procession

Subsequently, the data was copied to a Google Sheets sheet suggestively called "sursa intermediara pivotare" / "intermediary source for pivoting" (tinyurl.com/yyy58j5z), after which two pivot tables were created (Figure no. 2). The results of the latter (except the total) have been

1 http://www.bvb.ro/TradingAndStatistics/Statistics/ GeneralStatistics copied into two distinct Google Sheets named "Nr.distinct județe proveniență auditori pers.fizice" I Distinct number of counties of origin for auditors as individuals (tinyurl.com/y58f3hkl) and "Nr.auditori pers.fizice"/ Number of auditors as individuals (tinyurl.com/y4245bbk). 
Figure no. 2. Creating two pivot tables in Google Sheets starting from the first data source in order to quantify the number of auditors as individuals and

the distinct number of counties of their origin for each graduation year

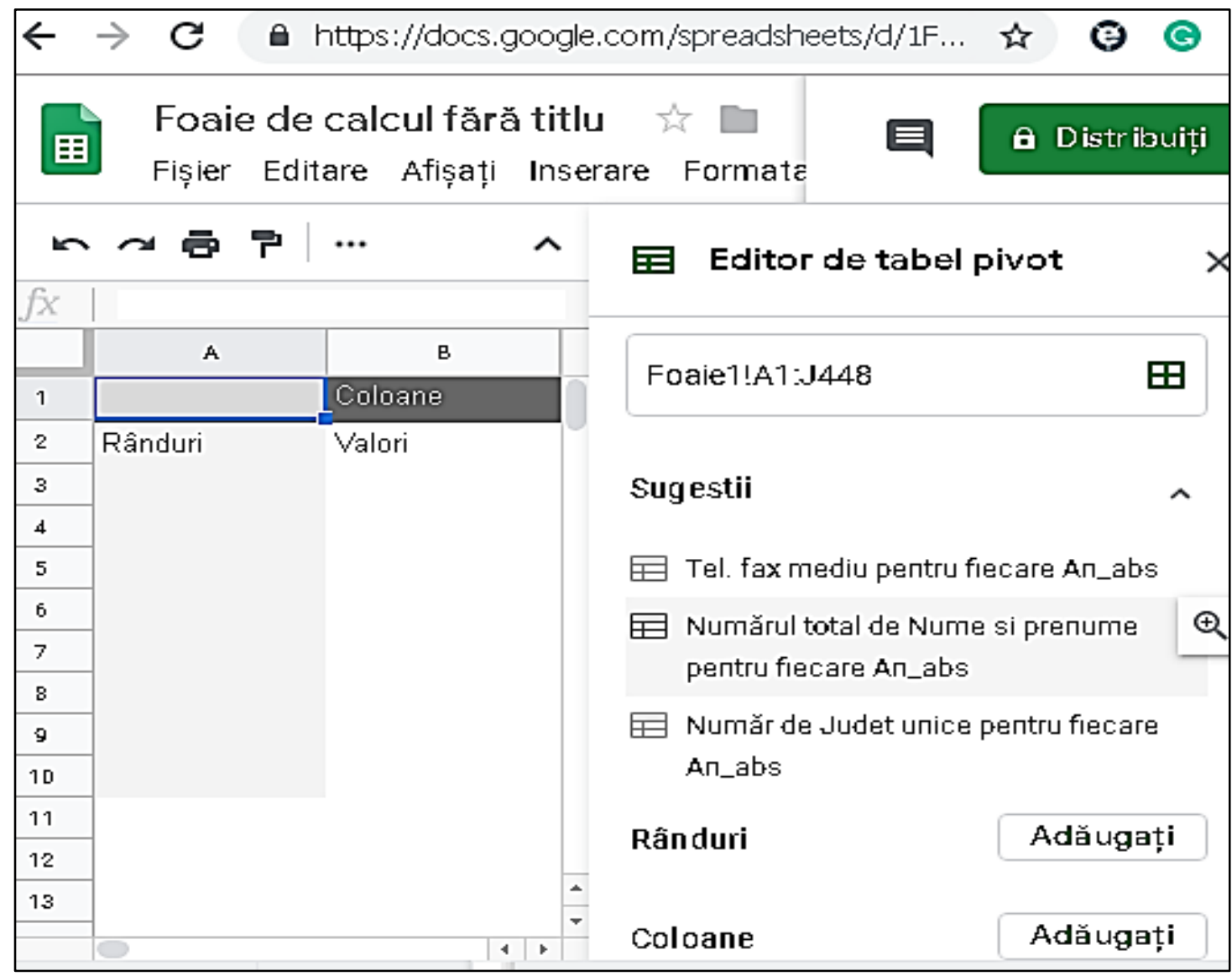

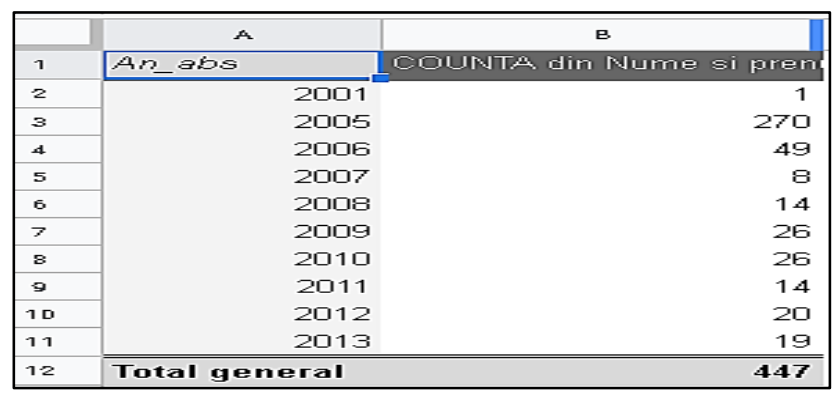

Source: Own procession

These resulting Google Sheets were then shared (Figure no. 3) with the account associated with the GiPlot online tool. Next, each of the two URLs was taken in turn (type https://doc.google.com/spreadsheets/d/...)

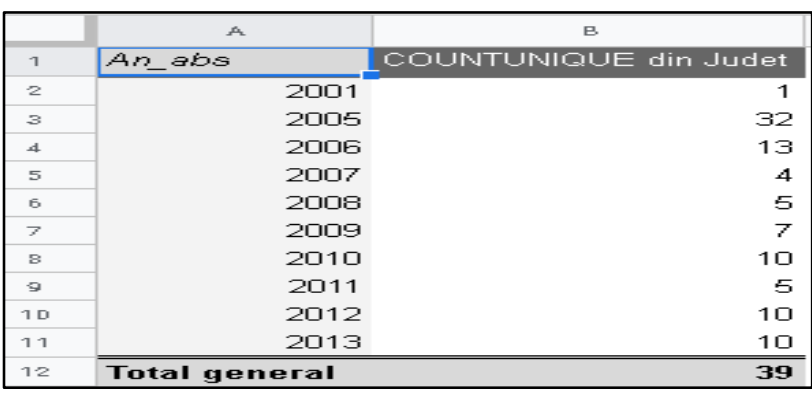

corresponding tho those two Google Sheets, and will be inserted into the corresponding box in the main window of the GiPlot tool (Try-It section) and taking care to act immediately on the Refresh button (Figure no. 4). 
Figure no. 3. Sharing the contents of the two distinct sheets with results from pivoting with the account associated with the GiPlot online application to let it read and represent them

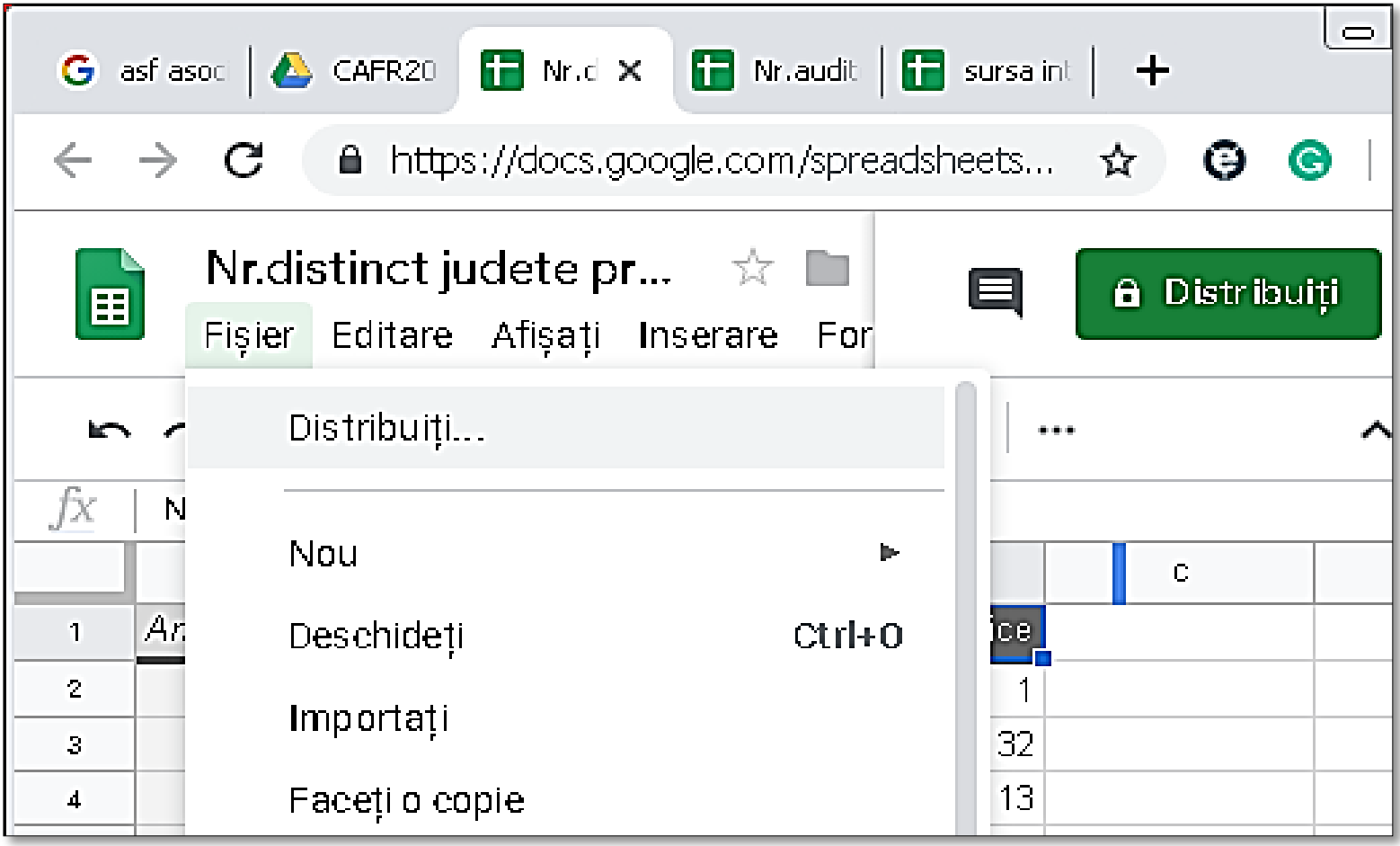

Colaborați cu alți utilizatori

Obțineți linkul care poate fi trimis $\leftrightarrow$

Utilizatori

$\therefore$ g.interactive.plot@gmail.com $\times$

Cine are acces

‥ Anumite persoane au acces

Modificați. .

- Daniel Homocianu (dvs.)

- dan.homocianu@gmail.com

Este proprietar(ă)

- $G$ Interactive Plot

$\therefore$ g.interactive.plot@gmail.com

\begin{tabular}{|c|}
\hline Este proprietar(ă) \\
Poate edita \\
Poate comenta \\
$\sim$ Poate vizualiza
\end{tabular}

Source: Own procession 


\section{Figure no. 4. Interactive representation of data obtained after the pivoting process using GiPlot}

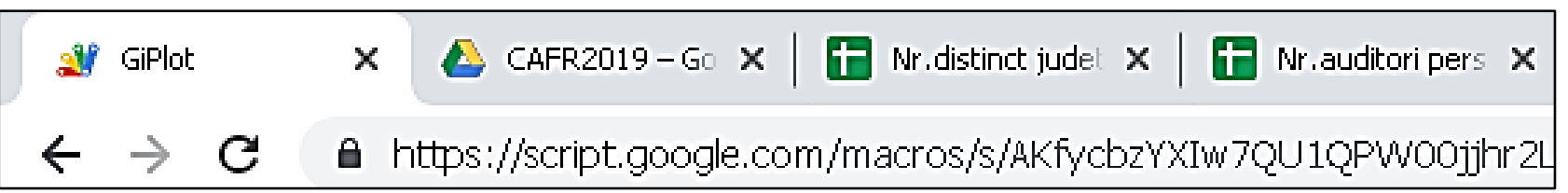

Your sheet's URL: https://docs.google.com/spreadsheets/d/11xufqcg0-qt Hm TeXgG3YvwHHzUw5mDf89vLh76 SPY5 Y/edititgid=0

patsin LineChart $\bigcirc$ AreaChart $\bullet$ LineChart $\bigcirc$ SoatterChart $\bigcirc$ ColumnChart

$\checkmark$ Nr.distinct judete prov.auditori pers.fizice

An_abs $2.005 \square 2.013$

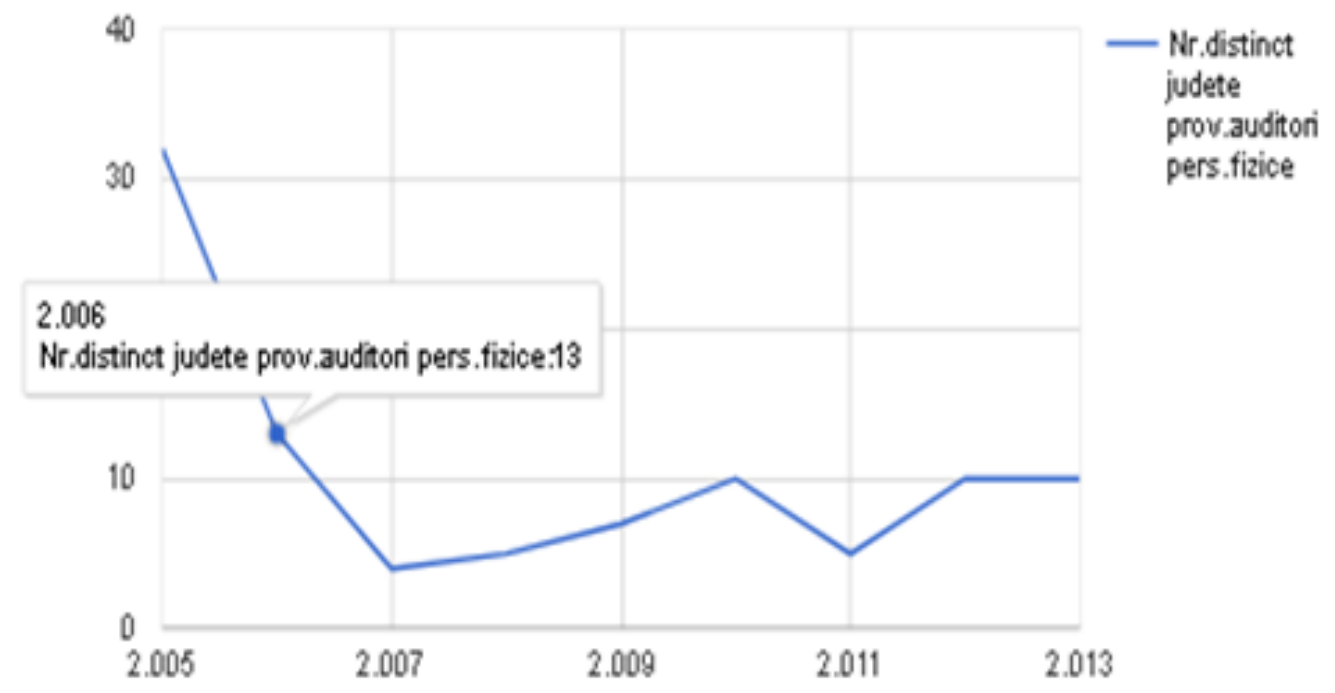

\begin{tabular}{rr} 
An_abs & Nr.distinct judete prov.auditori pers.fizice \\
2.005 & 32 \\
2.006 & 13 \\
2.007 & 4 \\
2.008 & 4 \\
2.009 & 5 \\
2.010 & 7 \\
2.011 & 10 \\
2.012 & 5 \\
\hline
\end{tabular}

Source: Own procession

No. 4(156)/2019 
Later we can filter on the time axis (e.g.. 2005-2013, Figure no. 4) and we will be able to get immediate feedback in the form of related data, by touching with the cursor (the Mouse Over effect) of a point of interest of a series on the graph, with the immediate highlighting of the value associated with a particular temporal moment (e.g. 13 distinct counties for 2016).

The second scenario may be of interest to the financial auditor's work both through an ex post analysis of the maximum and minimum points using financial data from the Bucharest Stock Exchange and by an inter-indices correlation analysis available in the specific data source.

In this scenario corresponding to the second dataset previously mentioned in the data and methods section, we started by simply copying the source data into a new Google Sheet (tinyurl.com/y5o5gjwk, Figure no. 5).

\section{Figure no. 5. Integrating the data from the second source into a new Google Sheet}

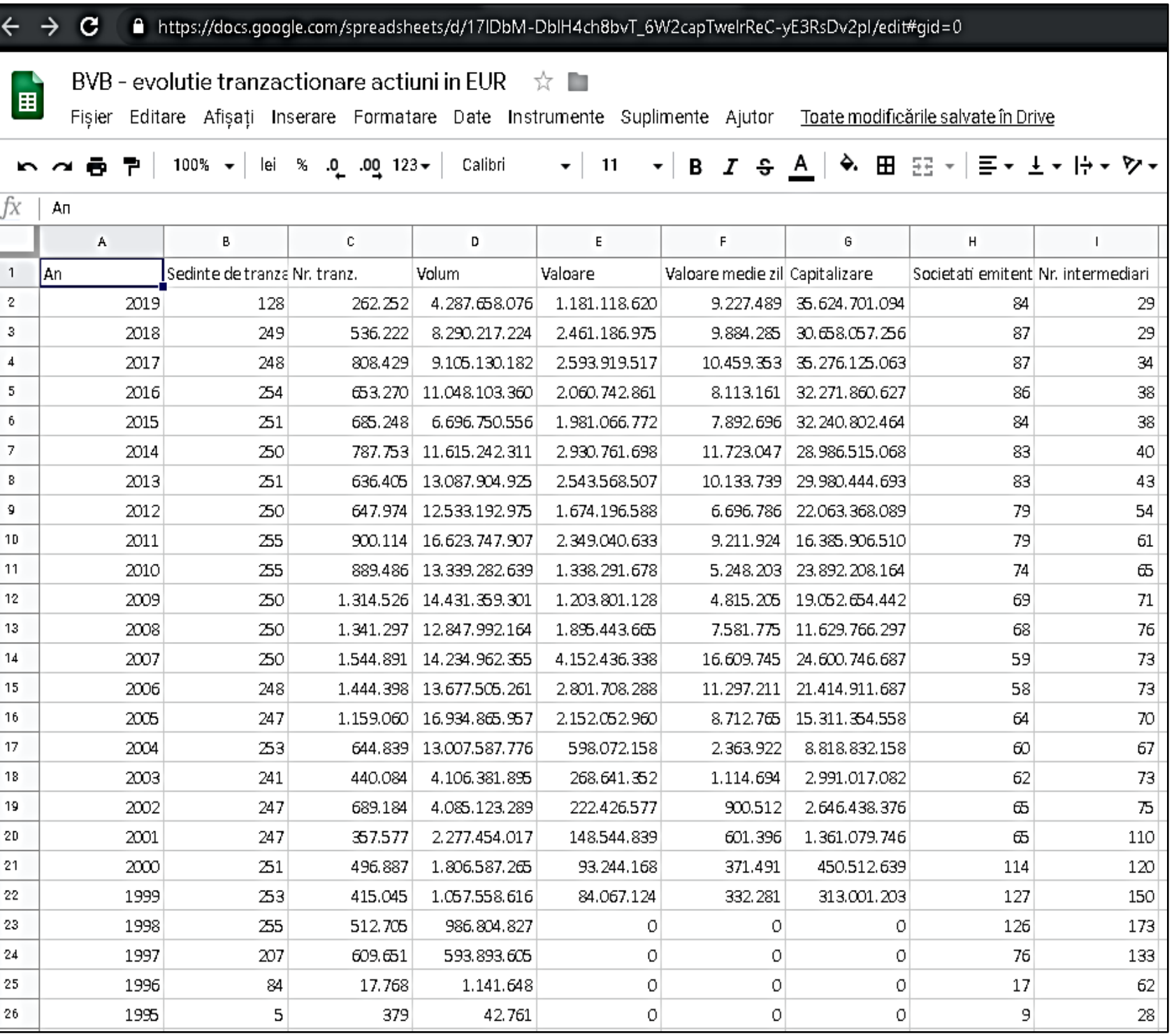

Source: Own procession 
Later, we have allowed the read of data using the GiPlot application simply by sharing the Google Sheet (Figure no. 5) with the aforementioned account,

g.interactive.plot@gmail.com, after which we were able to represent the time series using the same representation tool above and starting from explicitly specifying the URL of the sheet with data about the evolution of trading of shares on the BVB, with the expression of the value in Euros.

An important observation in this context is the one related to the inclusion in a certain representation based on time series only of those series that have a common expression (Figure no, 6) as measurement unit used (e.g. all expressed as value in EUR, all expressed in a certain number of units such as: meetings, transactions, companies and intermediaries).

\section{Figure no. 6. Representing time series and avoiding semantic errors by selecting only those variables with expression in the same measurement unit}

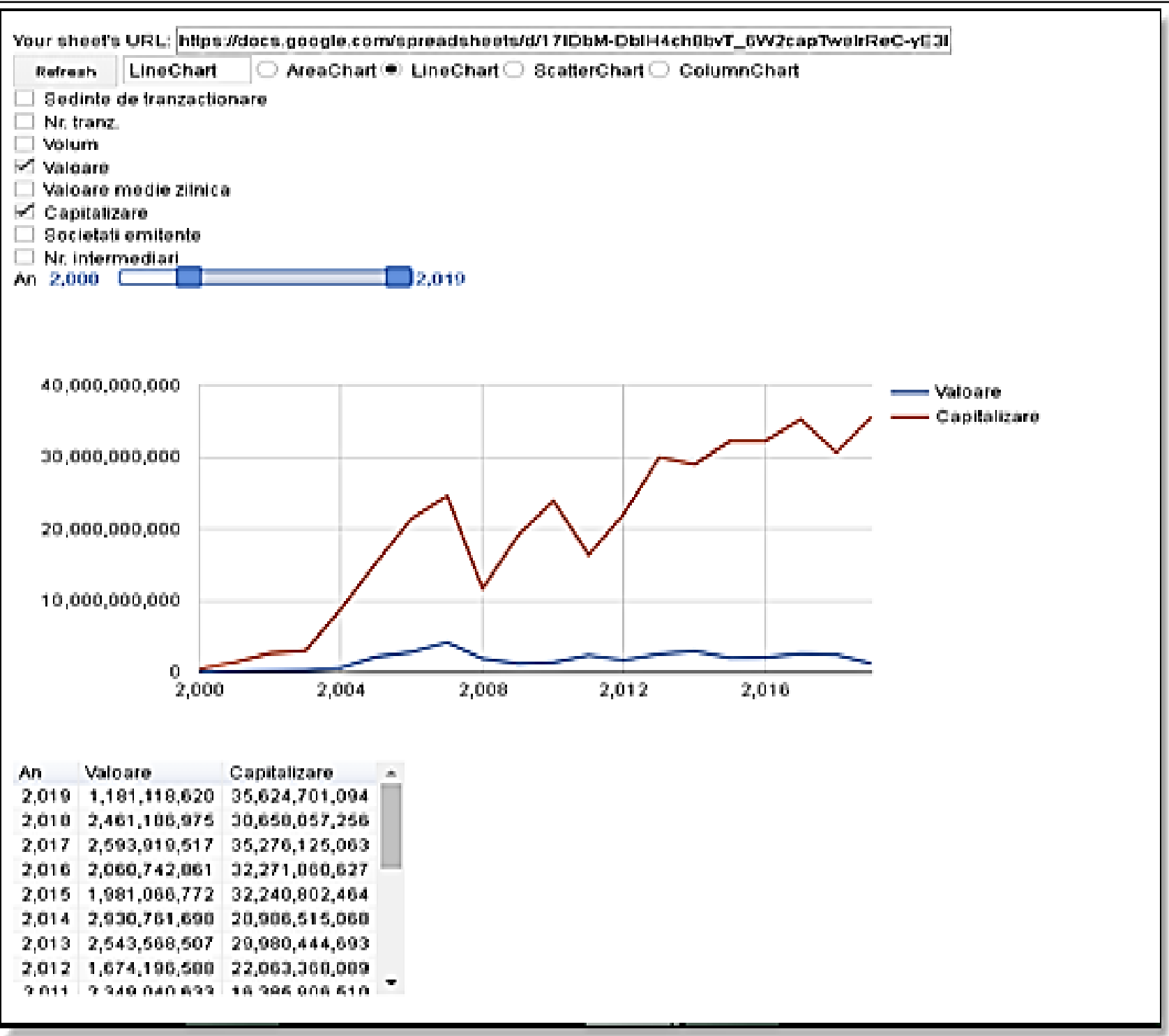

Source: Own procession

No. 4(156)/2019 


\section{Figure no. 7. Identifying the start of the economic and financial decline in Romania}

\section{by identifying the maximum number of transactions at BVB}

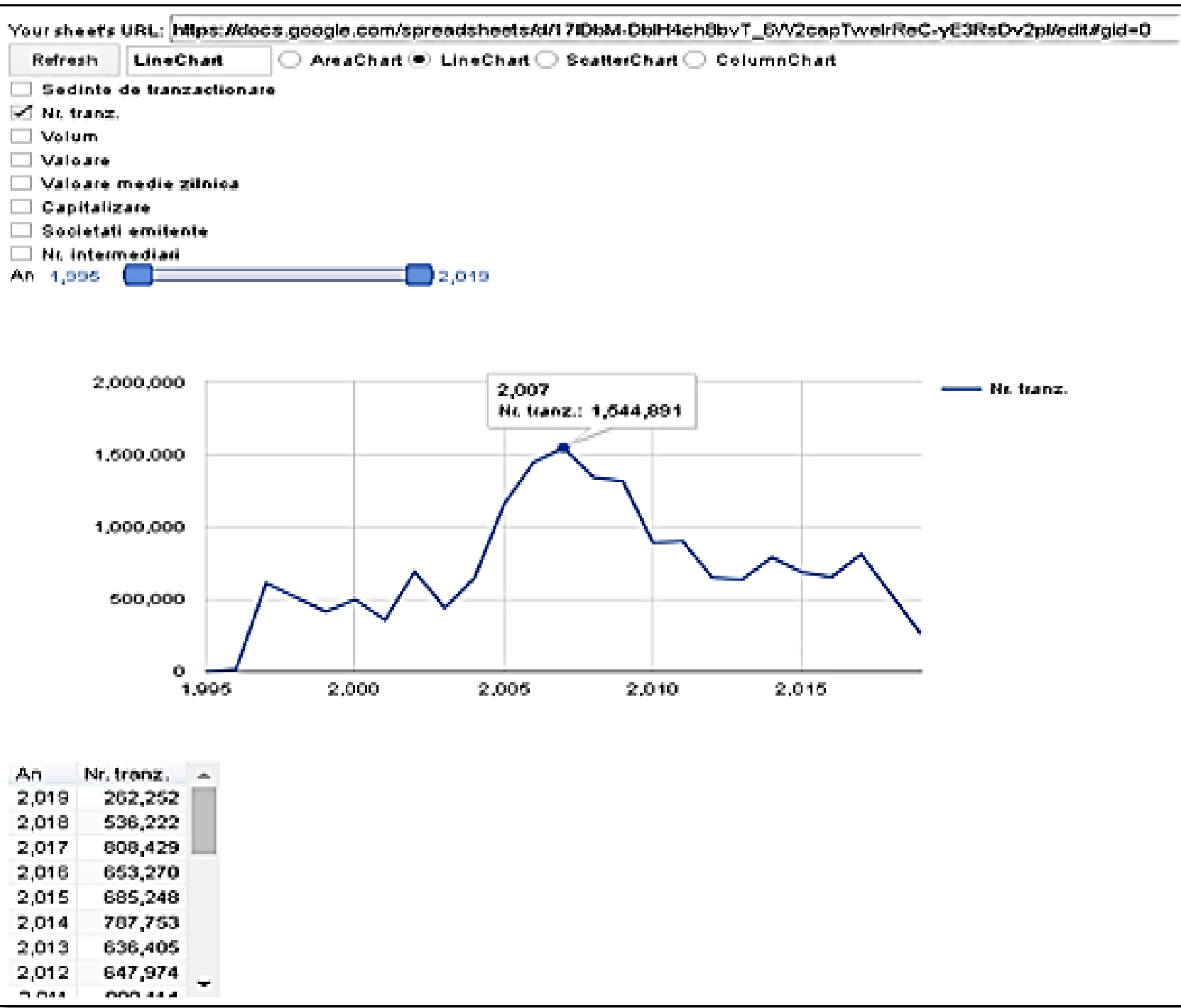

Source: Own procession

The time series have a great power of suggestion, especially when it comes to a posteriori analysis of some phenomena starting from a consistent volume of historical data. They can lead to the validation of certain moments that characterize the onset of overall socioeconomic phenomena, such as a crisis. (Badea, 2012). In Figure no. 7, the year 2007 corresponds to the maxim volume of transactions at BVB, after which a fall of this indicator may be reported, which can easily be associated with the economic and financial crisis that began worldwide at the end of 2007 and the beginning of 2008 .

The same year, 2007, is the one in which the maximum value for the daily average of transactions with shares expressed in Euros was recorded (Figure no. 8) and a value (59 in 2007) close to the minimum (58 in 2006) for the index referring to the number of issuing companies, as seen in Figure no. 9. 


\section{Figure no. 8. Identifying the onset of the economic-financial decline by visualizing the maximum point of the} daily average value of the BVB transactions

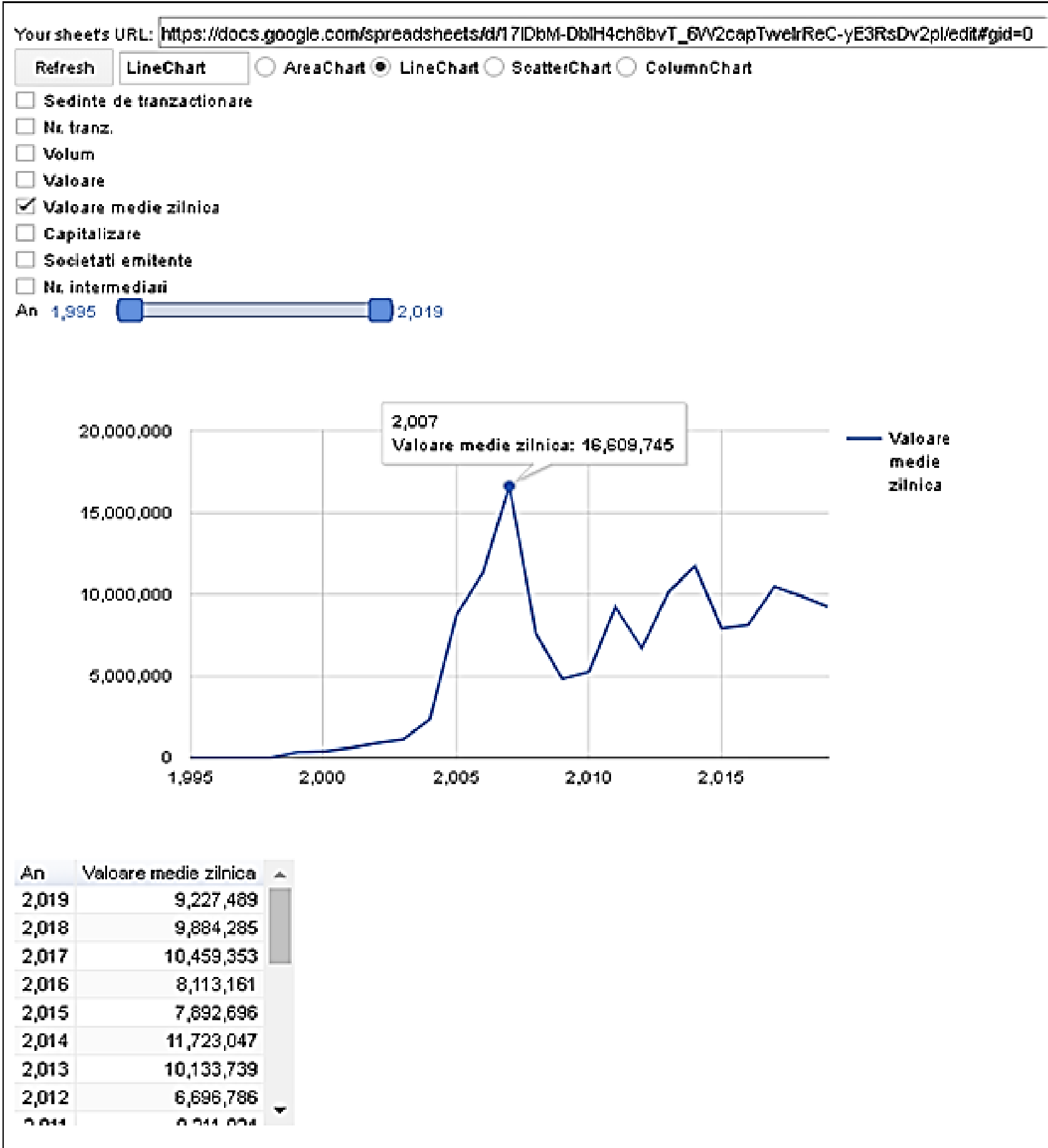

Source: Own procession 
Figure no. 9. Identifying the starting point of the economic and financial decline by finding the minimum

points related to the indicator related to the number of the issuers of shares

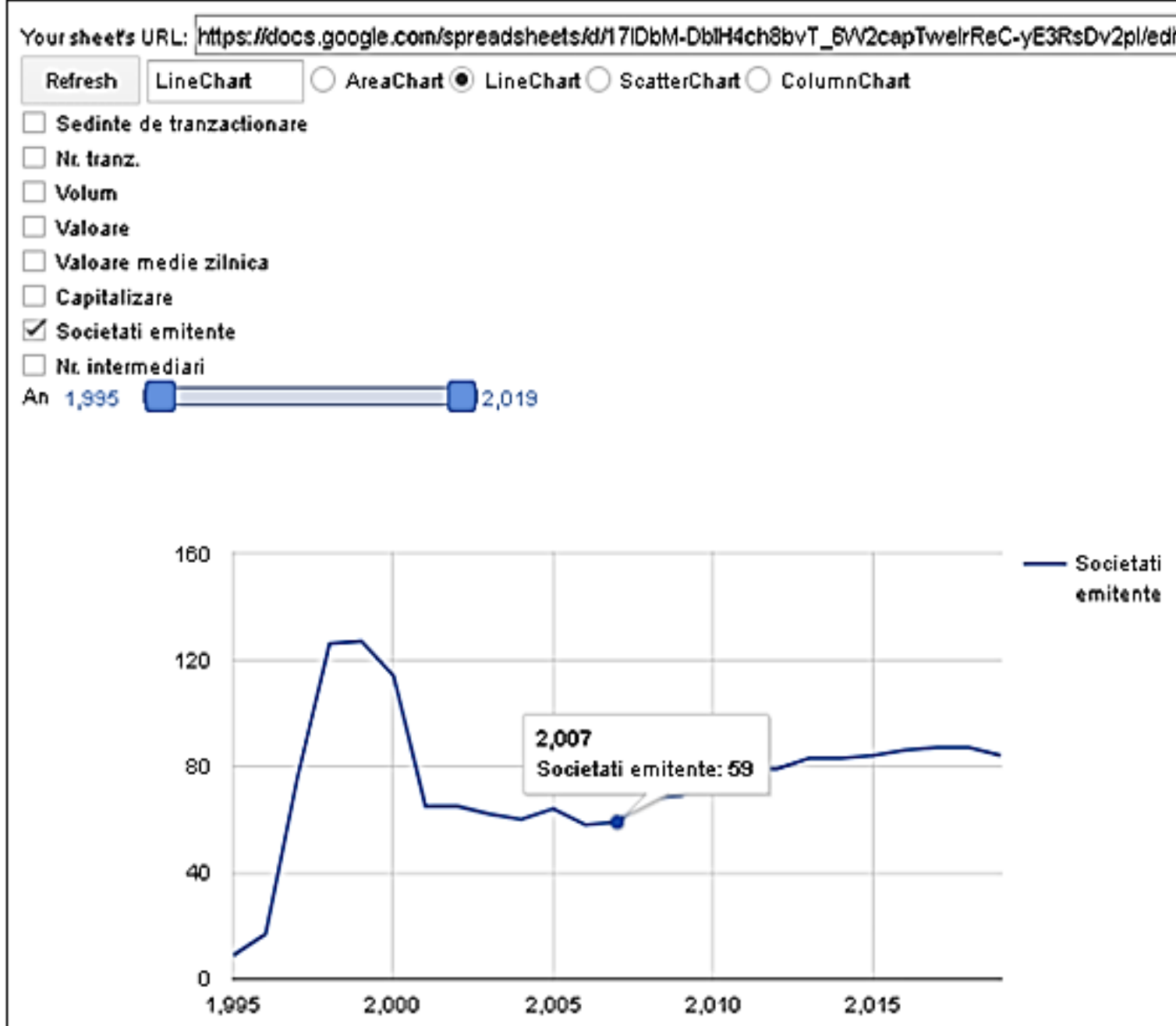

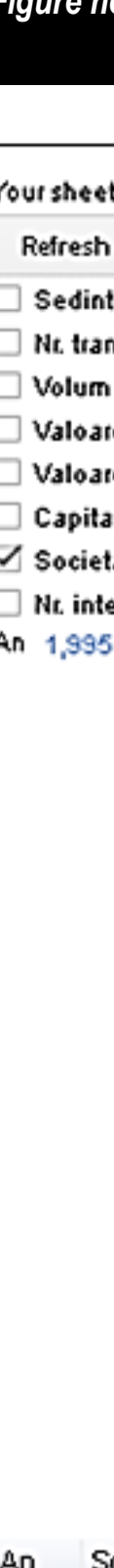

An Societati emitente

$2,019 \quad 84$

$2,018 \quad 87$

$2,017 \quad 87$

$2,016 \quad 86$

$2,015 \quad 84$

$2,014 \quad 83$

$2,013 \quad 83$

$2,012 \quad 79$

7nd4 $7 n$

Source: Own procession 
A minimum number of steps is required for switching from time series-based representations to correlation charts (Figures no. 10 and 11). Thus, we will consider the example in which we will be interested in how the capitalization (market value of the shares) is correlated with the other variables. As such, we'll start by inserting a new empty column on the left in the Google Sheets online spreadsheet, after which we will move here the values in the column for the capitalization indicator and we will sort everything up by the values of the latter, which has now become the first column.

\section{Figure no. 10. Identify the correlation between capitalization ( $X$ axis) and the number of intermediates of transactions with shares at BVB ( $Y$ axis)}
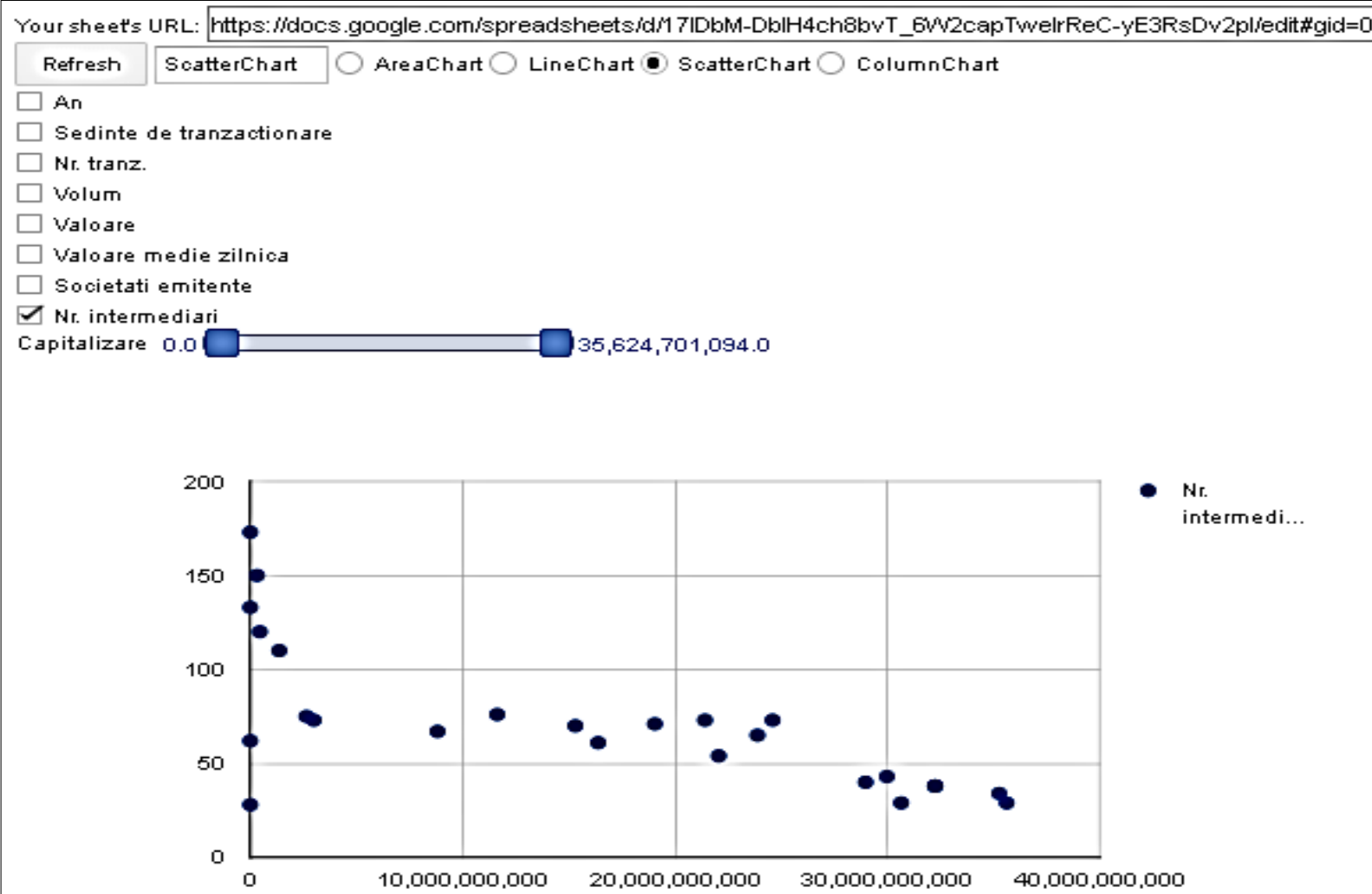

\begin{tabular}{r|r|r|} 
Capitalizare & Nr. intermediari \\
\hline 0 & 173 \\
0 & 133 \\
\hline 0 & 62 \\
\hline 0 & 28 \\
\hline $313,001,203$ & 150 \\
\hline $450,512,639$ & 120 \\
\hline $1,361,079,746$ & 110 \\
\hline $2,646,438,376$ & 75 \\
\hline 7 nn1 117 non & 72 \\
\hline
\end{tabular}

Source: Own procession 


\section{Figure no. 11. The same correlation above explored through the reversal of the axes: the number of} intermediates of transactions with shares at BVB ( $X$ axis) and the capitalization ( $Y$ axis)

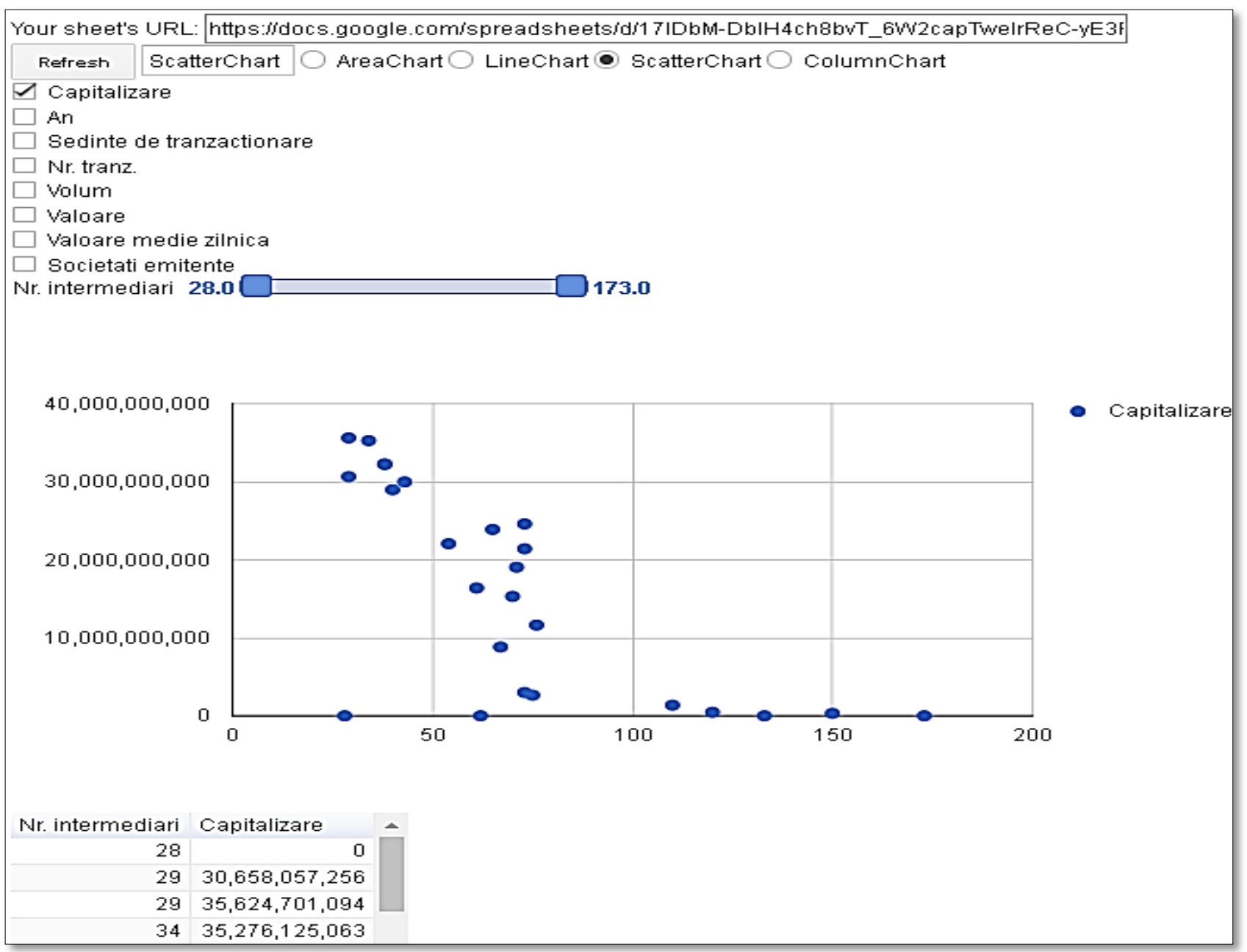

Source: Own procession

Later, we will act by changing the chart type (Scatter / Cloud of points), selecting all variables and pressing the button Refresh in the GiPlot online application.

If we only retain the variable corresponding to the number of intermediates of brokerage transactions in the form of shares, we will immediately notice a negative correlation between it and the capitalization value in both directions. More precisely, the higher the value of the second, the lower the value of the first one (Figure no. 10) and vice versa (Figure no. 11). For the situation presented in Figure no. 11, we have previously proceeded as above, with the mention that this time the column corresponding to the number of intermediates has been moved in such a way that it became the first and the entire set of data has been reordered ascendingly by the values of this variable.

\section{Conclusions}

In this paper, the benefits of interactive visual simulation applications in the spectral analysis of financial and audit data are argued.

For a better example, the chosen tool was GiPlot. This is a simple and easy-to-use application when it comes to 
visual online exploration of data. This is especially about data that can be taken in the spreadsheet format and which folds on the specifics of the online use with the Google Sheets tool which is compatible both as format and usage possibilities with Microsoft's corresponding well-known application (Office Excel).

The source data considered in this material has a strong link with the financial field and the one of financial audit, both by its nature and the one of the potential applications, exploitation and interpretation possibilities as well as the conclusions that can be derived from it.
We believe that through those two examples selected for this material, we are able to outline some strengths related to the benefits of using the GiPlot online tool in the auditing work. These examples correspond to usage scenarios where the issue of carrying out ex-post analyzes arises, both from the perspective of evolution and inter-index correlation. In both situations we start from possibilities of selecting different data sources and transparent and real time highlighting the results of biaxial filtering and graphical elements directly selected from the interactive representation component that provides real support for comparisons that are so useful in performance, efficiency and effectiveness analysis.

\section{REFERENCES}

1. Badea, L., The Impact of the Financial Crisis on the Romanian Capital Market in European Context, Theoretical and Applied Economics, Vol. XIX (2012), No. 3(568), pp. 26-39

2. Bertoneche, M. L., Spectral analysis of stock market prices, Journal of Banking \& Finance, Vol. 3, Issue 2, 1979, 201-208

3. Harvey, A. C., Spectral Analysis in Economics, Journal of the Royal Statistical Society. Series D (The Statistician), Vol. 24, No. 1 (Mar., 1975), 1-36

4. Homocianu, D., Airinei, D., On-line Dynamic Dashboards in Audit Activities, Audit Financiar, no. 5 (125) (2015), 91-100, (Year XIII), ssrn.com/id=2602661

5. Homocianu, D., Airinei, D., Turturean C.I., An interdisciplinary analysis with data mining and visualization tools applied on multiple and multisource time series - The case of the forest fund in Romania, Audit Financiar, no. 3/2018; 151(3): p. 382-397

6. Homocianu, D., Homocianu, M., GiPlot: An interactive cloud-based tool for visualizing and interpreting large spectral data sets, Spectrochimica Acta Part A: Molecular and
Biomolecular Spectroscopy, Vol. 209, 15 February 2019, p. 234-240

7. Homocianu, D., Sireteanu, N.A., Dospinescu, O., Airinei, D., An analysis of scientific publications on "Decision Support Systems" and "Business Intelligence" regarding related concepts using Natural Language Processing tools, Proceedings of the IE 2019 International Conference, Bucharest, pp. 99-104, www.conferenceie.ase.ro, https://ssrn.com/id=3400671

8. Sharda, R., Delen, D., Turban, E., Business Intelligence and Analytics: Systems for Decision Support, Pearson, 2014

9. ${ }^{* * *}$, New Employee Guide for External Public Auditors. Steps to follow and useful information for newly employed people, 2016, http://www.curteadeconturi.ro /Regulamente/GHID_ang_nou.pdf

10. ${ }^{* * *}$, Glossary of terms used in financial control, http://ier.gov.ro/wp-content /uploads/publicatii/Pais2_studiu3_anexe_ro.pdf

11. ${ }^{* * *}$, General methodological rules for the organization and operation of internal audit, http:// legislatie.just.ro/Public/DetaliiDocument/21247 